\title{
PENGARUH PEMANFAATAN ABU PECAHAN TERUMBU KARANG DAN ABU SEKAM PADI SEBAGAI PENGGANTI SEMEN TERHADAP KUAT TEKAN BETON
}

\author{
Nuzshi Ramahayati ${ }^{1)}$, Yuzuar Afrizal ${ }^{1}$, Mukhlis Islam ${ }^{1)}$ \\ ${ }^{1)}$ Program Studi Teknik Sipil, Fakultas Teknik, Universitas Bengkulu \\ Corresponding Author: yuzuar.afrizal@ gmail.com
}

\begin{abstract}
Abstrak
Semen portland merupakan jenis semen yang harganya relatif mahal apabila digunakan pada konstruksi-konstruksi yang memerlukan persyaratan yang sederhana. Pemanfaatan bahan lokal menggunakan abu pecahan terumbu karang dan abu sekam padi merupakan salah satu solusi. Penelitian ini bertujuan untuk mengetahui nilai kuat tekan beton pada setiap variasi penggantian sebagian semen yang digunakan yaitu 2,5\%, 5\%, 7,5\% dan 10\%, dimana setiap variasi terdiri dari $70 \%$ abu pecahan terumbu karang dan $30 \%$ abu sekam padi dari volume semen yang digunakan. Benda uji berbentuk kubus dengan ukuran $(15 \times 15 \times 15) \mathrm{cm}$ sebanyak 20 benda uji. Campuran adukan beton sesuai SNI 03-2834-2000 menggunakan nilai faktor air semen 0,5 dan slump 60-100 mm. Hasil kuat tekan beton variasi setiap penambahan persentase mengalami peningkatan dan penurunan dari hasil kuat tekan beton normal sebesar $368,24 \mathrm{~kg} / \mathrm{cm}^{2}$. Peningkatan maksimum terjadi pada kuat tekan beton variasi $7,5 \%$ sebesar $384,76 \mathrm{~kg} / \mathrm{cm}^{2}$ dan mengalami penurunan kuat tekan beton variasi $10 \%$ sebesar $367,40 \mathrm{~kg} / \mathrm{cm}^{2}$.
\end{abstract}

Kata kunci: abu pecahan terumbu karang, abu sekam padi, kuat tekan

\begin{abstract}
Portland cement is a relatively expensive type of cement when used on constructions requiring simple requirements. Local material utilization using ash fragments of coral reefs and rice husk ash is one of the solutions. The objectives of this study is to determine the value of concrete compressive strength in each variation of cement replacement used were $2.5 \%, 5 \%, 7.5 \%$ and $10 \%$, each variation consists of $70 \%$ ash fragment of coral reefs and $30 \%$ rice husk ash from the volume of cement used. The cube specimen with a size of $(15 \times 15 \times 15) \mathrm{cm}$ as many as 20 specimen were prepared. Concrete mixture according to SNI 03-2834-2000 used 0.5 cement water ratio and 60-100 $\mathrm{mm}$ of slump. The result of the compressive strength of concrete variation every percentage increase has increased and decreased from the result of the normal concrete compressive strength of $368.24 \mathrm{~kg} / \mathrm{cm}^{2}$. Maximum increase occurred in the concrete compressive strength variation $7.5 \%$ of $384.76 \mathrm{~kg} / \mathrm{cm}^{2}$ and decreased on the concrete compressive strength variation $10 \%$ of $367.40 \mathrm{~kg} / \mathrm{cm}^{2}$.
\end{abstract}

Keywords: ash fragments of coral reefs, rice husk ash (ASP), compressive strength

\section{PENDAHULUAN}

Beton adalah campuran antara agregat halus, agregat kasar, air dalam jumlah tertentu dan semen portland atau semen hidraulik dengan atau tanpa bahan tambah. Campuran tersebut bila dituang dalam cetakan dan didiamkan, maka akan menjadi keras. Kekuatan, keawetan dan sifat beton tergantung pada sifat-sifat dasar penyusunnya, selama penuangan adukan beton, cara pemadatan 
dan perawatan selama proses pengerasan (Kardiyono, 2002).

Semen memiliki komposisi berupa $\mathrm{CaO}$ dari batuan kapur sebesar $70 \%$, $\mathrm{SiO}$ sebagai sumber silika sebesar 20\%, alumina dan bahan aditif yang terdiri dari $\mathrm{MgO}$ sebesar $1 \%, \quad \mathrm{FeO}$ sebesar $1 \%$ dan gypsum CaSO sebesar 5-10\% serta $2 \mathrm{H}_{2} \mathrm{O}$ untuk mengatur waktu ikat semen (Nurzal dan Mahmud, 2013). Abu pecahan terumbu karang (APTK) dan abu sekam padi (ASP) dapat digunakan sebagai pengikat alternatif yaitu bahan pengganti semen.

Pecahan terumbu karang dibakar dan digerus hingga menjadi butiran dan abu. Jenis material yang penting bagi produksi semen adalah yang kaya mengandung kapur (Hendra dan Sina, 2003).

Tabel 1. Komposisi Terumbu Karang

\begin{tabular}{cll}
\hline No & Parameter & Jumlah (\%) \\
\hline 1 & $\mathrm{SiO}_{2}$ & 2,37 \\
\hline 2 & $\mathrm{MgO}_{2}$ & 24,80 \\
\hline 3 & $\mathrm{Fe}_{2} \mathrm{O}_{3}$ & 0,24 \\
\hline 4 & $\mathrm{Na}_{2} \mathrm{O}$ & 1,27 \\
\hline 5 & $\mathrm{CaCO}_{3}$ & 73,76 \\
\hline
\end{tabular}

Abu sekam padi memiliki unsur kimia silika ( $\mathrm{SiO} 2)$ yang cukup tinggi dan Kalsium Oksida $(\mathrm{CaO})$ (Gurning dan Nursyamsi, 2014). unsurunsur ini memiliki sifat-sifat pozzolan yang dapat meningkatkan kinerja material beton dan dapat meminimalkan penggunaan semen sekaligus menghasilkan mutu beton yang optimum.

Penelitian ini bertujuan untuk mengetahui pengaruh kuat tekan beton pada setiap variasi penggantian sebagian semen yang digunakan yaitu $2,5 \%, 5 \%, 7,5 \%$ dan $10 \%$, dimana setiap variasi terdiri dari $70 \%$ abu pecahan terumbu karang dan 30\% abu sekam padi dari volume semen yang digunakan.

\section{METODE PENELITIAN}

Metode penelitian yang digunakan adalah metode eksperimen dengan melakukan penggantian sebagian semen dengan $70 \%$ abu pecahan terumbu karang dan 30\% abu sekam padi dalam pembuatan beton dengan variasi sebesar $2,5 \%, 5 \%, 7,5 \%$ dan $10 \%$. Benda uji beton direndam selama 26 hari, kemudian dikeluarkan pada suhu ruang dan di uji tekan pada umur 28 hari.

\section{Material yang digunakan}

Bahan yang digunakan dalam penelitian ini terdiri dari semen jenis PCC (Portland Composite Cement) sesuai SNI 15-7064-2004 dengan kemasan $50 \mathrm{~kg}$. Agregat kasar batu split dengan ukuran diameter maksimal $2 \mathrm{~cm}$ diperoleh dari Kabupaten Bengkulu Utara, agregat halus di peroleh dari Curup, Kabupaten Rejang Lebong. Air yang digunakan berasal dari air sumur di sekitar Laboratorium Konstruksi dan Teknologi Beton Program Studi Teknik Sipil Fakultas Teknik Universitas Bengkulu. Pecahan terumbu karang diolah dengan cara membakar manual sampai terumbu karang terlihat rapuh dan menjadi seperti kapur, yang kemudian dilakukan penyaringan.

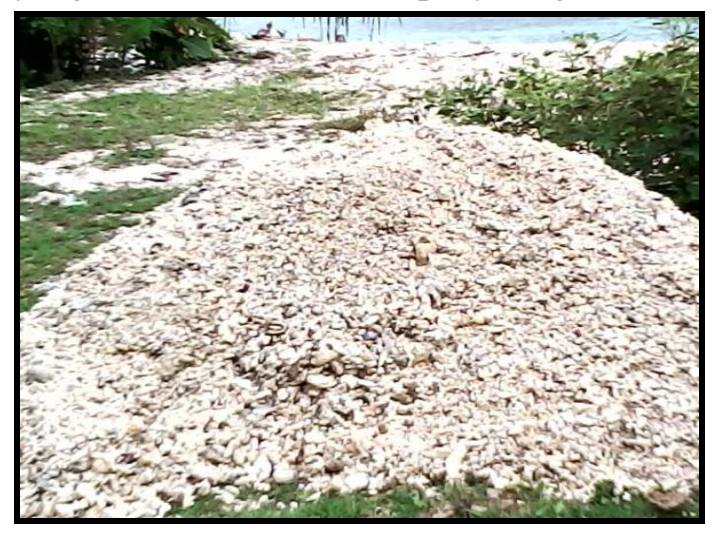

Gambar 1. Pecahan Terumbu Karang 



\section{Komposisi campuran beton}

Komposisi campuran beton dalam penelitian ini dibuat berdasarkan SNI 032834-2000 dengan menggunakan nilai FAS sebesar 0,5 dan nilai slump 60-100 mm. Kemudian material semen dilakukan penggantian sebesar $2,5 \%, 5 \%, 7,5 \%$ dan $10 \%$, dimana

setiap variasi terdiri dari $70 \%$ abu pecahan terumbu karang dan $30 \%$ abu sekam padi. Benda uji pada penelitian ini dibuat menggunakan cetakan berbentuk kubus dengan ukuran $(15 \times 15 \times 15) \mathrm{cm}$, sebanyak 20 benda uji dengan 4 sampel beton normal dan 16 beton dengan variasi.

Tabel 2. Komposisi Material Pembuatan Benda Uji

\begin{tabular}{c|cccccc}
\hline & \multicolumn{6}{|c}{ Material atau Bahan $(\mathrm{kg})+30 \%$} \\
\cline { 2 - 7 } Variasi & Split & Pasir & Semen & Air & ASP & APTK \\
\hline Normal & 19,46 & 9,58 & 7,9 & 3,95 & 0 & 0 \\
\hline $2,50 \%$ & 19,46 & 9,58 & 7,7 & 3,95 & 0,02 & 0,14 \\
\hline $5 \%$ & 19,46 & 9,58 & 7,51 & 3,95 & 0,03 & 0,27 \\
\hline $7,50 \%$ & 19,46 & 9,58 & 7,31 & 3,95 & 0,05 & 0,41 \\
\hline $10 \%$ & 19,46 & 9,58 & 7,11 & 3,95 & 0,07 & 0,54 \\
\hline Total & & & & & & \\
\hline Material & 37,53 & 19,75 & 47,9 & 97,28 & 0,17 & 1,36 \\
\hline
\end{tabular}

\section{Pengujian benda uji}

Pengujian dilakukan dengan alat uji tekan pada umur 28 hari, di catat beban maksimumnya.

Nilai kuat tekan beton diperoleh berdasarkan SNI 03-1974-1990 dan dihitung dengan rumus:

Kuat tekan beton $=\frac{P}{A}(\mathrm{~kg} / \mathrm{cm} 2)$

Keterangan :

$\mathrm{P}=$ Beban maksimum $(\mathrm{kg})$

$\mathrm{A}=$ Luas penampang benda uji $(\mathrm{cm} 2)$

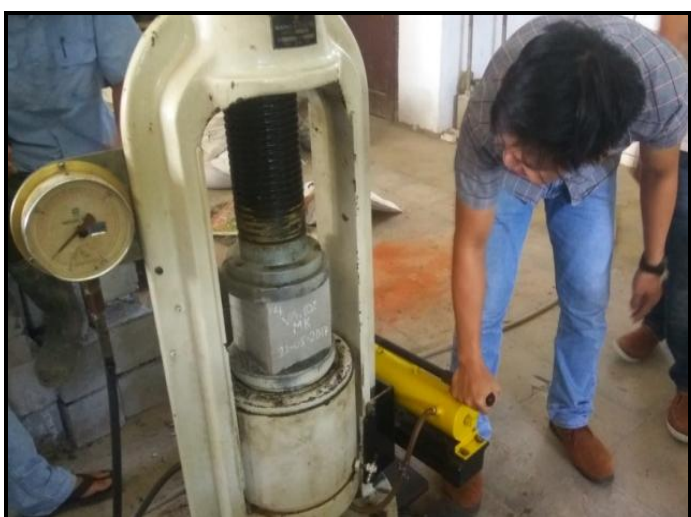

Gambar 2. Pengujian Kuat Tekan

\section{HASIL DAN PEMBAHASAN}

\section{Pengujian slump beton}

Sebelum dilakukan pencetakan benda uji, dilakukan pemeriksaan slump beton dengan tujuan untuk mengontrol penggunaan air dari hasil mix desain dan slump yang terukur serta air yang tersisa. Penggantian abu pecahan terumbu karang dan abu sekam padi pada campuran beton mempengaruhi kebutuhan air campuran, hal ini disebabkan abu sekam padi bersifat mengikat air. Hasil pengujian slump pada campuran beton segar diperoleh nilai slump yang sesuai rencana, yaitu berada diantara 60-100 mm. Nilai Slump dan penggunaan air dapat dilihat pada Tabel 3.

Tabel 3. Hasil Uji Slump dan Sisa Penggunaan Air

\begin{tabular}{lcc}
\hline Beton & $\begin{array}{c}\text { Slump } \\
\text { rata-rata } \\
\text { (cm) }\end{array}$ & $\begin{array}{c}\text { Sisa } \\
\text { Penggunaan } \\
\text { Air }(\mathbf{g r})\end{array}$ \\
\hline Normal & 7,9 & 400 \\
\hline Variasi 2,5 \% & 6,6 & 310 \\
\hline Variasi 5 \% & 7,6 & 391 \\
\hline Variasi 7,5 \% & 8,3 & 193 \\
\hline Variasi 10\% & 7,2 & 221 \\
\hline
\end{tabular}

\section{Pemeriksaan berat isi}

Sebelum benda uji di uji tekan, dilakukan pengujian berat isi, dimana rata-rata berat pada angka $2300 \mathrm{~kg} / \mathrm{m}^{3}$. Penggantian semen 
dengan abu pecahan terumbu karang dan abu sekam padi mempengaruhi berat isi beton. Beton variasi $10 \%$ mengalami peningkatan berat isi terhadap berat isi normal sebesar $2385,27 \mathrm{~kg} / \mathrm{m}^{3}$. Berat isi beton normal dan beton variasi yang dihasilkan dari penelitian ini dapat dilihat pada Tabel 4.

Tabel 4. Hasil Berat Isi Beton Normal dan Beton Variasi Penggantian

\begin{tabular}{cc}
\hline Beton & $\begin{array}{c}\text { Berat Isi rata-rata } \\
\left(\mathbf{k g} / \mathbf{m}^{\mathbf{3}}\right)\end{array}$ \\
\hline Normal & 2373,08 \\
\hline Variasi 2,5 \% & 2382,19 \\
\hline Variasi 5\% & 2382,64 \\
\hline Variasi 7,5\% & 2383,92 \\
\hline Variasi 10\% & 2385,27 \\
\hline
\end{tabular}

\section{Kuat tekan beton}

Kuat tekan beton umur 28 hari dengan variasi penggantian semen $2,5 \%, 5 \%, 7,5 \%$ dan $10 \%$ umumnya mengalami peningkatan dan mulai menurun pada variasi penggantian $10 \%$. Peningkatan kuat tekan beton terbesar pada variasi penggantian 7,5\% dengan kuat tekan rata-rata 384,76 $\mathrm{kg} / \mathrm{cm}^{2}$ dan penurunan kuat tekan beton hanya terjadi pada variasi penggantian $10 \%$ dengan kuat tekan $367,40 \mathrm{~kg} / \mathrm{cm}^{2}$. Kuat tekan rata-rata beton dapat dilihat pada Tabel 5 dan Gambar 3.

Tabel 5. Kuat Tekan Beton Normal dan Beton Variasi Penggantian

\begin{tabular}{|c|c|c|c|c|c|}
\hline \multirow[b]{2}{*}{ No } & \multicolumn{5}{|c|}{ Kuat Tekan Beton $\left(\mathrm{kg} / \mathrm{cm}^{2}\right)$} \\
\hline & Normal & $2,50 \%$ & $5 \%$ & $7,50 \%$ & $10 \%$ \\
\hline 1 & 371,19 & 378,39 & 373,95 & 362,63 & 380,72 \\
\hline 2 & 369,85 & 370,66 & 394,2 & 395,59 & 353,64 \\
\hline 3 & 359,95 & 389,47 & 369,95 & 402,96 & 364,22 \\
\hline 4 & 371,97 & 376,01 & 382,86 & 377,84 & 371,02 \\
\hline $\begin{array}{l}\text { Kuat } \\
\text { Tekan } \\
\text { rata-rata }\end{array}$ & 368,24 & 378,64 & 380,24 & 384,76 & 367,4 \\
\hline
\end{tabular}

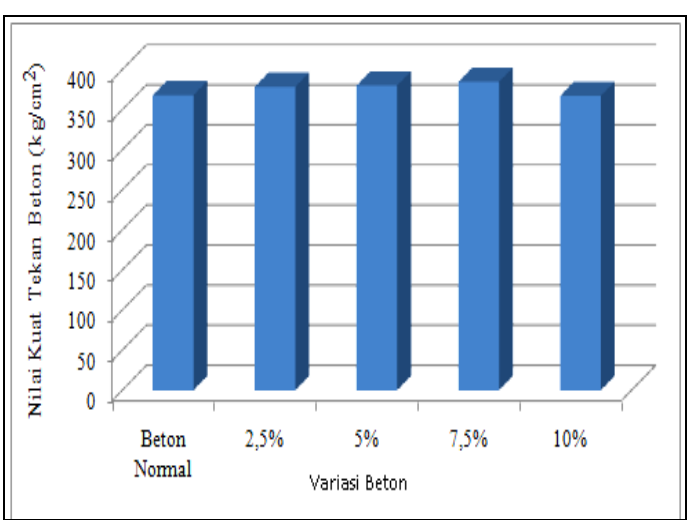

Gambar 3. Diagram kuat tekan rata-rata beton

\section{Selisih Kuat Tekan Beton}

Selisih kenaikan kuat tekan beton variasi penggantian semen terhadap beton normal terbesar pada variasi $7,5 \%$ dengan kenaikan $4,49 \%$. Sedangkan selisih penurunan kuat tekan beton terdapat pada variasi penggantian semen $10 \%$ terhadap beton normal sebesar $0,23 \%$. Selisih kuat tekan beton disajikan pada Tabel 6 dan dapat juga dilihat dalam bentuk grafik pada Gambar 4 .

Tabel 6. Selisih Kuat Tekan Beton

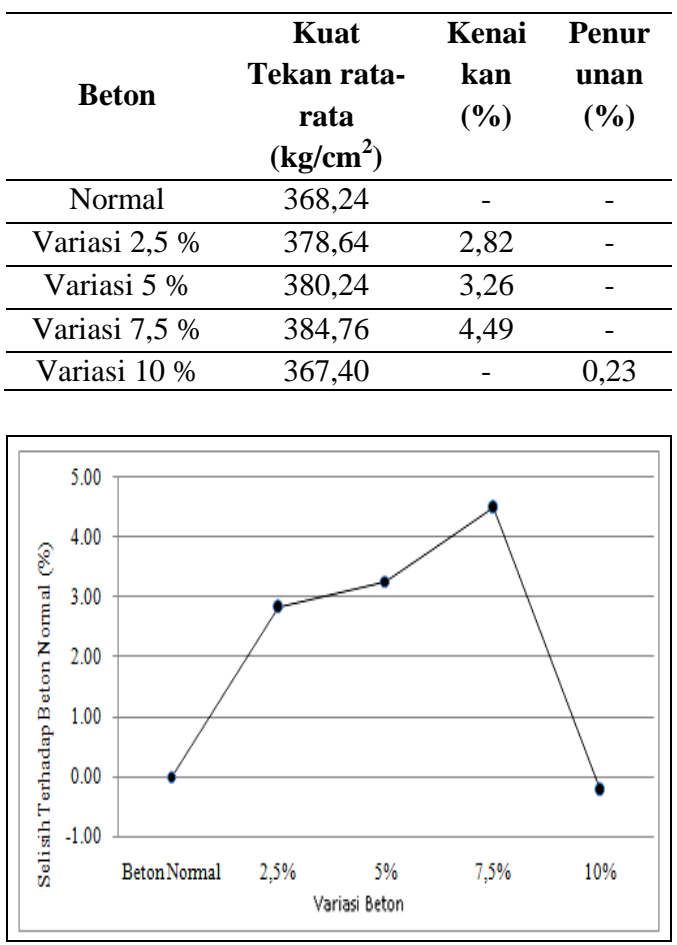

Gambar 4. Grafik selisih kuat tekan beton variasi terhadap beton normal. 


\section{KESIMPULAN}

Kesimpulan yang dapat diambil dari data hasil penelitian mengenai pengaruh pengganti sebagian semen dengan $70 \%$ abu pecahan terumbu karang dan 30\% abu sekam padi terhadap nilai kuat tekan tekan beton normal adalah sebagai berikut:

1. Penggantian sebagian semen dengan $70 \%$ abu pecahan terumbu karang dan $30 \%$ abu sekam padi, dapat mempengaruhi kuat tekan beton.

2. Peningkatan hasil kuat tekan beton variasi $2,5 \%, 5 \%$ dan $7,5 \%$ terhadap beton normal berturut-turut adalah $2,82 \%, 3,26 \%$ dan $4,49 \%$.

3. Terjadi penurunan hasil kuat tekan beton pada variasi penggantian $10 \%$ terhadap beton normal sebesar $0,23 \%$.

4. Hasil persentase peningkatan kuat tekan terbesar beton terdapat pada variasi 7,5\% sebesar $384,76 \mathrm{~kg} / \mathrm{cm}^{2}$ atau 38,48 MPa dengan selisih 4,49\% terhadap beton normal.

\section{DAFTAR PUSTAKA}

Gurning, J.S dan Nursyamsi. 2014. Pengaruh Penambahan Abu Sekam Padi Dan Cangkang Kemiri Terhadap Sifat Mekanis Beton, Jurnal Teknik Sipil USU 5(2).

Hendra dan Sina. 2003. Potensi Pengunaan Batu Karang Pulau Timor Sebagai Agrgegat Kasar pada Beton, Fakultas Teknik Sipil Kristen Petra, Surabaya.

Kardiyono, T. 2002. Buku Ajar Teknologi Beton. Universitas Gajah Mada. Yogyakarta.

Nurzal dan J, Mahmud. 2013. Pengaruh Komposisi Fly Ash Terhadap Daya Serap Air Pada Pembuatan Paving block, Institut Teknologi Padang, Padang.
SNI 032834 2000.Tata Cara Pembuatan Rencana Campuran Beton Normal. Badan Standarisasi Nasional.

SNI 15-7064-2004. Semen Portland Komposit. Badan Standarisasi Nasional.

SNI 03-1974-1990. Metode Pengujian Kuat Tekan Beton. Badan Standarisasi Nasional. 